\title{
TEKNIK PENDEDERAN KERANG ABALON (Haliotis squamata) DI BALAI BESAR PENELITIAN DAN PENGEMBANGAN BUDIDAYA LAUT GONDOL-BALI
}

\section{Separating Techniques Shellfish Abalone (Haliotis squamata) at the Center for Research and Development of Marine Aquaculture Gondol-Bali}

\author{
Nizar Afiansyah Loekman ${ }^{1}$, Abdul Manan ${ }^{2}$, Muhammad Arie ${ }^{2}$ dan Prayogo ${ }^{2}$. \\ ${ }^{1}$ Program Studi Budidaya Perairan, Fakultas Perikanan dan Kelautan, Universitas Airlangga, Surabaya \\ ${ }^{2}$ Departemen Manajemen Kesehatan Ikan dan Budidaya Perairan, Fakultas Perikanan dan Kelautan, Universitas \\ Airlangga, Surabaya \\ *nizar.afiansyah-13@ fpk.unair.ac.id
}

\begin{abstract}
Abstrak
Kerang abalon merupakan salah satu komoditas laut yang memiliki nilai ekonomis tinggi, karena daya jualnya dipasar ekspor sudah terbukti hingga mencapai $\mathrm{Rp} 600.000,-$ / kg. Salah satu faktor pengembangan abalon menjadi suatu industri akuakultur di Indonesia disebabkan adanya permintaan konsumsi pasar yang terus meningkat, sementara itu jumlah pasokan produk budidaya masih terbatas dan masih mengandalkan penangkapan dari alam. Tujuan dari Praktek kerja Lapang adalah untuk mengetahui dan mempelajari Teknik Pendederan Kerang Abalon (Haliotis squamata) di Balai Besar Penelitian dan Pengembangan Budidaya Laut Gondol-Bali. Kegiatan Praktek Kerja Lapang akan dilaksanakan di Balai Besar Penelitian dan Pengembangan Budidaya Laut (BBPPBL) Dusun Gondol, Desa Penyabangan, Kecamatan Gerokgak, Kabupaten Buleleng, Bali, Provinsi Bali. Praktek Kerja Lapang dilaksanakan pada 18 Januari 2016 - 18 Februari 2016. Kegiatan ini menggunakan metode deskriptif dengan pengambilan data meliputi data primer dan data sekunder. Pengambilan data dilakukan dengan cara observasi, wawancara, partisipasi aktif, dan studi pustaka. Pendederan kerang abalon dilaksanakan oleh pihak Hatchery Abalon di Balai Penelitian dan Pengembangan Budidaya laut Gondol-Bali meliputi pemanenan juvenile, pemindahan ke keranjang pendederan, pemberian pakan, kualitas air, seleksi kerang abalon dan pemeliharaan. Kualitas pendederan kerang abalon yang dilakukan oleh BBPPBL Gondol-Bali sudah memenuhi standar yang baik untuk budidaya kerang abalon.
\end{abstract}

Kata kunci: Abalon (Haliotis squamata), Pendederan dan Seleksi Benih

Abstract

Shellfish abalone sea is one commodity that has high economic value, because the selling power of export markets has proven to $\mathrm{Rp} 600.000,-$ / kg . One factor abalone development into an aquaculture industry in Indonesia due to the market consumption demand continues to increase, while the number of supply aquaculture products is still limited and still rely on arrests of nature. The purpose of the Practice Field work is to know and learn the technique of separating the shells of abalone (Haliotis squamata) at the Center for Research and Development of Marine Aquaculture Gondol - Bali. Activity Field Work Practice will be held at the Center for Research and Development of Marine Aquaculture ( BBPPBL ) Hamlet Gondol , Penyabangan , Gerokgak, Buleleng, Bali , Bali Province . Activities will be implemented on January 18, 2016 - February 18 , 2016. The working methods used in Field Work Practice is descriptive method with data collection included primary data and secondary data. Data were collected by observation, interview, active participation , and literature. Separating shellfish abalone Abalone Hatchery carried out by the Center for Research and Development in Aquaculture Gondol sea - Bali include juvenile harvesting, transfer to cart nursery, feeding , water quality, selection and maintenance of abalone shells. Quality nursery abalone shells carried by BBPPBL Gondol - Bali already meet good standards for the cultivation of abalone shells.

Keywords: Abalon (Haliotis squamata), Separating and Size Grading

\section{PENDAHULUAN}

Abalon (Haliotis spp.) saat ini telah mulai dibudidayakan di Indonesia. Abalon merupakan hewan bersifat low trophic level saat larva Abalon memakan bentik diatom dan mikroalga saat dewasa Abalon 
memakan rumput laut atau makroalga kegiatan budidaya Abalon di Indonesia biayanya relatif murah. Hal ini terkait dengan kondisi geografis dan ekologis Indonesia yang mendukung pertumbuhan makroalga sebagai pakan alami Abalon (Setyono, 2004). Oleh karena itu, dari sisi ekonomis biaya produksi komoditas ini relatif murah. Hal inilah yang menarik dari komoditas abalon. Produksi benih yang berkelanjutan dan terkontrol memberi kesempatan bahwa budidaya abalon dapat dikembangkan di masa yang akan datang.

Selama ini produksi Abalon diperoleh dari hasil penangkapan di alam. Penangkapan seringkali dilakukan dengan cara yang tidak selektif sehingga dapat mengakibatkan kelestarian sumberdaya abalon tersebut menjadi terancam. Untuk itu perlu dilakukan produksi benih abalon dalam suatu sistem budidaya secara terkontrol.

Adanya pengembangan abalon disebabkan adanya permintaan dan konsumsi pasar yang terus meningkat, sementara produk semakin terbatas karena sebagian besar hanya diperoleh dari penangkapan di alam. Oleh sebab itu, budidaya abalon merupakan suatu langkah yang tepat dalam memenuhi permintaan pasar tersebut.

Sejak tahun 2007 Balai Besar Penelitian dan Pengembangan Budidaya Laut - Gondol Bali, telah melakukan penelitian dibidang budidayakan Abalon. Sampai saat ini telah diperoleh teknologi yang utuh dari pembenihan sampai pembesaran, budidaya Abalone sudah dibagi menjadi beberapa segmen usaha yaitu pembenihan, pendederan dan pembesaran.

Pembagian ini dilakukan agar menyingkat waktu produksi yang cukup lama, sehingga biaya yang dikeluarkan memungkinkan masyarakat kecil dapat melakukan kegiatan usaha dibidang ini. Tujuan Praktek Lapang ini adalah untuk mengetahui dan mempelajari teknik pendederan kerang Abalone (Haliotis squamata) atau yang biasa disebut kaki kuning yang berada di Balai Besar Penelitian dan
Pengembangan Budidaya Laut Gondol, Bali.

\section{METODOLOGI \\ Waktu dan Tempat}

Praktek kerja lapang ini dilaksanakan di Unit Balai Besar Penelitian dan Pengembangan Budidaya Laut (BBPPBL) Dusun Gondol, Desa Penyabangan, Kecamatan Gerokgak, Kabupaten Buleleng, Bali, Provinsi Bali, kegiatan ini dilaksanakan pada tanggal 18 Januari 2015 sampai 18 Februari 2016.

\section{Metode Penelitian}

Praktek Kerja Lapang ini menggunakan metode observasi yang dilakukan dengan mengamati langsung pemeliharaan pada juvenil kerang abalone Haliotis squamata di mana meliputi persiapan Bak, kontruksi Bak, persiapan juvenil, pemberian pakan, pemberantasan hama dan penyakit, serta sarana dan prasarana yang menunjang untuk kegiatan ini.

\section{HASIL DAN PEMBAHASAN Pendederan Kerang Abalon}

Pendederan kerang abalon (Haliotis squamata) di Balai Besar Penelitian dan Pengembangan Budidaya Laut Gondol dilakukan dengan sistem indoor untuk menjaga suhu tetap stabil, selain itu abalon jika ditempatkan pada tempat yang gelap atau sedikit cahaya pergerakannya menjadi aktif Abalon lebih banyak mengkonsumsi pakan yang disediakan dalam keranjang pendederan dan sehingga Abalon lebih cepat tumbuh besar dan siap dipindahkan ke kolam pembesaran.

Didalam ruangan terdapat enam bak yang terbuat dari beton bak pendederan kerang abalon mempunyai ukuran 2 meter x 3 meter dan tinggi 1,5 meter setiap kolam berisikan 28-30 buah keranjang yang berukuran $20 \mathrm{~cm}$ x $15 \mathrm{~cm}$ dengan tinggi $10 \mathrm{~cm}$ dan didalamnya terdapat 100 ekor kerang abalon ukuran $2-5 \mathrm{~cm}$ hal ini sesuai dengan Rusdi dkk (2010) bahwa pada keranjang keranjang pendederan berisi 100-125 ekor Kerang Abalon. Di 
setiap kolam menggunakan sistem sirkulasi untuk menjaga kualitas air agar kandungan amoniak dari kotoran dan sisa pakan yang berada di air cepat terbuang sehingga terdapat saluran pada pipa pembuangan dan masuknya air, didalamnya juga terdapat enam aerasi yang selalu menyala agar kandungan oksigen didalam kolam tinggi.

\section{Seleksi dan Penebaran}

Seleksi untuk larva yang akan ditebarkan pada keranjang pendederan dilakukan dengan cara memilih larva yang ada pada rearing plate ukuran $0,5 \mathrm{~cm}$ sampai $1 \mathrm{~cm}$. Pemilihan larva menggunakan alat berupa spatula dikarenakan larva abalon pada ukuran $0,5 \mathrm{~cm}$ sampai 1 $\mathrm{cm}$ sudah cukup lengket pada rearing plate sehingga perlu menggunakan spatula untuk memindahkan larva kerang abalon, larva yang telah diambil dengan spatula diletakkan pada keranjang pendederan yang berisikan Ulva sp. sebanyak setengah kilogram untuk pakan awal pada masa pendederan. Kepadatan awal untuk proses pendederan dengan ukuran kerang abalon $0,5 \mathrm{~cm}$ sampai $1 \mathrm{~cm}$ berjumlah 250 ekor/ keranjang, setelah mencapai ukuran $2 \mathrm{~cm}$ sampai $3 \mathrm{~cm}$ kerang abalon akan diseleksi lagi bertujuan untuk mengurangi kepadatan dan kompetisi dalam mengkonsumsi pakan sehingga kerang abalon dapat tumbuh dengan optimal menjadi 100 ekor/ keranjang.

\section{Pakan}

Pakan untuk pendederan kerang abalon ukuran $0,5 \mathrm{~cm}$ sampai $1 \mathrm{~cm}$ masih berupa Ulva sp. dikarenakan tekstur Ulva sp. lebih lembut, setelah ukuran mencapai $2 \mathrm{~cm}-3 \mathrm{~cm}$ baru pakan dicampur dengan Gracilaria sp hal ini sesuai dengan Rusdi dkk (2010) bahwa pakan yang paling disukai Abalon adalah Ulva sp. dikarenakan memiliki tekstur yang lembut dan mudah dicerna.

Pakan kerang abalon Ulva sp. didapat disekitar pantai dekat dengan saluran pembuangan yang berada dibela- kang balai sedangkan Gracilaria sp. yang didapat dari tambak didaerah Situbondo, setelah itu pakan tersebut dikumpulkan dalam kolam penampungan pakan yang berisi air laut setinggi $30 \mathrm{~cm}$ sampai $40 \mathrm{~cm}$ dan menggunakan sistem sirkulasi agar pakan tidak cepat busuk dan kotoran seperti lumpur dapat terlepas dari pakan.

Pengaturan dan pemberian pakan dengan cara menyiapkan pakan yang diambil pada bak penampungan dengan keranjang pakan sebanyak $20 \mathrm{~kg}$. Proses pertama dalam mengolah pakan adalah mencuci pakan pada bak dengan air laut mengalir sampai bersih dari kerang kecil sampai terlepas dari pakan kemudian dibilas dengan air tawar sebanyak dua kali untuk mematikan parasit yang berasal dari laut atau tambak.

Pemberian pakan pada setiap keranjang pendederan Abalon dilakukan secara adlibitum, proses terakhir adalah pengecekan pakan setiap 2-3 hari sekali untuk memastikan jumlah pakan pada keranjang pendederan abalon masih cukup.

\section{Pengelolaan Kualitas Air}

Pengeloalaan kualitas air pada kolam pendederan kerang abalon ini dengan cara memastikan bahwa sirkulasi air lancar. Karena sirkulasi berperan dalam mengeluarkan amoniak yang berasal dari kotoran dan sisa pakan yang jatuh ke dasar kolam pendederan sehingga kualitas air tetap terjaga. Aerasi pada tiap kolam harus berjalan lancar agar suplai oksigen pada kolam pendederan baik.

Pergantian air secara keseluruhan dilakukan setiap tiga hari sekali dengan cara membuka saluran pipa pembuangan outlet untuk membuang sisa pakan yang berada didasar kolam agar tidak menimbulkan amoniak. Pakan yang terdapat didasar akan kolam akan membusuk dan dapat menimbulkan amoniak sehingga menyebabkan kematian kerang abalon pada kolam pendederan.

Pada pengukuran kualitas air diperoleh $29^{\circ} \mathrm{C}$ dan salinitas $33 \mathrm{ppt}$ hal ini sudah sesuai dengan Irwan (2006) dan 
Setyono (2010), suhu yang optimal untuk abalon berkisar antara $24^{\circ} \mathrm{C}-30^{\circ} \mathrm{C}$, sedangkan salinitas optimum antara 30-35ppt. Menurut Fallu (1991), kisaran salinitas normal yang cocok untuk pertumbuhan abalon yaitu 33-35 ppt.

\section{Penanggulangan hama dan penyakit}

Hama pada pendederan kerang Abalon berupa kepiting kecil, kerang kecil dan udang-udang kecil yang berasal dari Gracilaria sp. Hal ini dikarenakan bentuk Gracilaria sp. yang menggerombol sehingga pada saat pencucian pakan yang kurang bersih hama masih menempel pada pakan dan masuk keranjang pendederan. Hama yang masuk menyerang dan berpengaruh pada kelangsungan hidup abalon dan kompetisi dalam mengkonsumsi pakan hal ini sesuai dengan Rusdi (2010) bahwa salah satu cara pencegahan penyakit adalah pakan yang diberikan harus dalam keadaan segar dan bersih. Sedangkan pada Ulva sp. tidak ditemukan hama, karena Ulva sp. diambil dari pinggir pantai dan betuknya seperti lembaran plastik sehingga pada saat pencuciannya tidak terdapat hama yang menempel.

Pada masa pendederan kerang abalon tidak ditemukan penyakit yang menyerang, setelah masa pendederan dipindah ke kolam pembesaran biasanya jika tidak disertai treatment akan terjadi stress pada kerang abalon. Kerang Abalon yang stress akan bergerak naik ke pinggir kolam dan berada di atas permukaan air dan akhirnya mati. Hal ini disebabkan kerang abalon berpindah tempat dari keranjang pendederan yang sedikit cahaya dan terbatas geraknya ke kolam pembesaran yang luas dan cahaya.

Cara penanganan diawali dengan sirkulasi air, kemudian ambil pakan dikarenakan pakan abalon berupa Gracilaria masih dalam keadaan hidup sehingga dapat terjadi persaingan dalam suplai oksigen, setelah itu berikan obat albazzu dengan dosis 15 gram kemudian tunggu sekitar hingga tiga jam sampai tidak ada kerang abalon yang bergerak keluar dari permukaan air, proses terakhir adalah nyalakan kembali sirkulasi air dan jangan memberi pakan terlebih dahulu agar kerang abalon dapat beradaptasi dengan lingkungan baru.

\section{Pemanenan}

Panen yang dilakukan bertujuan untuk proses selanjutnya yaitu pembesaran dengan kepadatan 2500 ekor per kolam, panen dilakukan ketika ukuran kerang abalon telah mencapai $3 \mathrm{~cm}$ sampai dengan $5 \mathrm{~cm}$. Untuk membedakan ukuran Abalon yang berbeda sehingga dapat meningkatkan pertumbuhan Abalon.

Peralatan yang digunakan pada saat pemanenan adalah spatula, pipa shelter, aerasi dan kolam indukan sedangkan untuk bahan cukup menggunakan air laut, albazzu, dan pakan jenis Gracilaria sp. proses pemanenan dilakukan dengan cara mengambil keranjang pada kolam pendederan dan kemudian menseleksi abalon yang sudah mencapai ukuran 3 sampai dengan $5 \mathrm{~cm}$, kemudian dilepas dengan spatula dan langsung ditaruh pada kolam pembesaran yang telah diberi albazzu agar kerang Abalon tidak mengalami stress.

\section{KESIMPULAN DAN SARAN Kesimpulan}

$\begin{array}{ccc}\text { Pendederan } & \text { Kerang } & \text { Abalon } \\ \text { (Haliotis squamata). dilakukan } & \text { dalam }\end{array}$ beberapa tahap yaitu pemanenan juvenil, seleksi ukuran, pemerataan jumlah media pendederan dan pemeliharaan. Berdasarkan pengamatan, puncak populasi kerang abalon pada keranjang pendederan rata-rata mencapai 250 ekor per keranjangnya pada awal pendederan dan mengalami pemerataan menjadi 100 ekor per keranjang setelah dua bulan awal pemanenan. Hasil pengamatan lingkungan atau pengukuran kualitas air diperoleh hasil suhu antara 24$30,5^{\circ} \mathrm{C}$ dan salinitas 31-32,6 ppt. Pemberian pakan berupa Ulva sp.

\section{Saran}

Berdasarkan hasil praktek kerja lapang yang telah dilakukan disarankan 
agar hal-hal yang telah memenuhi standar operasional prosedur dalam pemeliharaan kerang abalon dipertahankan untuk menjaga kualitas pembudidayaan kerang abalon (Haliotis squamata sp) yang dihasilkan. Selain itu, penyediaan Ulva sp. dalam masa awal pendederan sangat perlu diperhatikan karena jumlahnya di alam masih terbatas dan dipengaruhi oleh cuaca.

\section{DAFTAR PUSTAKA}

Capinpin, Jr.E.C. \& Corre, K.G. 1996. Growth rate of the Philippine abalone, Haliotis asinina fed an artificial diet and macroalgae. Aquaculture, 144(1-3): 81-89.

Dharma, B. 2008. Moluska unggulan Indonesia sebagai sumber pangan. Makalah dipresentasikan pada Seminar Moluska II. IPB. Bogor, $16 \mathrm{hlm}$.

Fallu, R. 1991. Abalone Farming. Fishing New Books. Inggris

Fallu, R. 1991. Abalone farming. Set by setrite typesetter limited Printed and bound in Great Britain by Harnolls, Bodmin, Conwail.

Fermin, A.C., Encena II, V.C., Suriawan, A., Hamka, I.J., Effendy, \& Kusumaningtyas, W. 2009. Abalone industry enhancement in eastern Indonesia. Australian Centre for International Agricultural Research. Final Report. No. FR2009-07. p. 19.

Giri, I.N.A., Sutarmat, T., Yudha, H., Rusdi, I., Pantjara, B., \& Rahmawati, R. 2010. Pembesaran abalon (Haliotis squamata) di rakit dengan sistem kurungan dan penjarangan. Laporan Teknis. Balai Besar Riset Perikanan Budidaya Laut, Gondol. Bali, 12 hlm.

Giri, I.N.A., Sutarmat, T., Yudha, H., Rusdi, I., Pantjara, B., \& Rahmawati, R. 2010. Pembesaran abalon (Haliotis squamata) di rakit dengan sistem kurungan dan penjarangan. Laporan Teknis. Balai
Besar Riset Perikanan Budidaya Laut, Gondol. Bali, 12 hlm.

Gordon, H.R. \& Cook, P.A. 2004. World abalone fisheries and aquaculture update: supply and market dynamics. J. Shellfish Res., 20: 567570.

Irwan, J.E. 2006. Pengembangan Budidaya Abalon (Haliotis asinina) Produksi Hatchery di Indonesia. Jurusan Perikanan, UNHALU, Kendari, Sulawesi Tenggara, $21 \mathrm{hlm}$

Priyambodo, B., Sofyan, Y., \& Jaya, I.B.M.S. 2005. Produksi benih tiram abalon (Haliotis asinina) di Loka Budidaya Laut Lombok. Prosiding Seminar Nasional Tahunan Hasil Penelitian Perikanan dan Kelautan. UGM. Yogyakarta, 5 hlm.

Rahmawati, R., 1., Rusdi dan B., Susanto. 2008. Studi tentang pertumbuhan abalon Haliotis squamata (reeve, 1846) dengan pemberian pakan makroalga yang berbeda. Presiding Seminar Nasional Perikanan 2008. Teknologi Budidaya Perikanan Sosial Ekonomi Kelautan dan Perikanan. STP Jakarta. 342-349 p.

Rahmawati, R., I. Rusdi, B. Susanto dan S. lsmi. 2009. produksi massal benih abalon Haliotis squamata (Reeve, 1846). Forum lnovasi Teknologi Akuakultur. Pusat Riset Perikanan budidaya, Surabaya. 11 hal. (In press)

Rusdi, 1., B., Susanto dan R., Rahmawati. 2009. Pemeliharaan abalon Haliotis squamata dengan sistem pergantian air yang berbeda. Presiding seminar Nasional Moluska. FPIK-IPB. Bogar. (lnpress)

Setyono, D. E. D,. 2009. Abalon Biologi dan Reproduksi. Lipi Press. Mataram.

Singhagraiwan, T. \& Doi, M. 1993. Seed production and culture of a tropical abalone Haliotis asinine, Linne. Department of Fisheries, Coastal 
Aquatic Feed Research Institute, Jatujak, Bangkok 10900. Thailand, p. 165-174.

Susanto B., A. Hanafi, Zafran dan S. 1smi. 2007. Pematangan gonad induk dan perbaikan kualitas benih abalon (Haliotis squamata). Laporan Teknis BBRPBL Gondol Bali. 17 hal.

Susanto, B., lbnu Rusdi, Suko lsmi, dan Riani Rahmawati. 2009. Pemeliharaan juvenil abalon (Haliotis squamata) turunan F-1 secara terkontrol dengan jenis pakan berbeda. 15 hal. (lnpress) 